\title{
Downloaded Work, Sideloaded Work, and Financial Circumstances: The Contemporary Worker's Experience of Equity and Need Principles
}

\author{
Atsushi Narisada ${ }^{1}$ (D) Philip J. Badawy ${ }^{2} \cdot$ Scott Schieman ${ }^{2}$
}

Accepted: 10 March 2021 / Published online: 8 April 2021

(C) The Author(s), under exclusive licence to Springer Science+Business Media, LLC, part of Springer Nature 2021

\begin{abstract}
People value being paid appropriately for their work — but national surveys indicate that many working adults report a discrepancy between what they actually earn and what they think they should justly earn. This evidence provides an impetus for examining the factors that shape workers' justice perceptions of earnings. The present study elaborates on two key distributive justice principles-equity and need-that guide people's ideas about their just reward. We ask: How do contemporary workers experience and understand the nature of work effort and need? We employ a mixed methods research design to answer this question. First, we analyze focus group interviews among workers in Toronto, Ontario $(N=22)$, and generate two novel hypotheses about the factors that shape workers' expectation for greater rewards: "downloaded" and "sideloaded" extra work that induce feelings of overwork, and rising cost of living and the associated financial strain. Second, drawing upon focus group narratives, we operationalize these concepts and test our hypotheses with a 2019 nationally representative sample of Canadian workers $(N=2,111)$. The results show that downloaded and sideloaded extra work shape greater reward expectations partly through the sense of overload, and rising cost of living and the associated financial strain also shape reward expectations. Furthermore, financial strain amplifies the link between extra work and greater reward expectations. We situate these findings within a broader discussion of the nature of effort and need among contemporary workers and its implications for justice perceptions.
\end{abstract}

Keywords Distributive justice $\cdot$ Equity $\cdot$ Need $\cdot$ Mixed methods

Atsushi Narisada

atsushi.narisada@smu.ca

1 Department of Sociology, Saint Mary's University, 923 Robie Street, Halifax, NS B3H 3C3, Canada

2 University of Toronto, Toronto, Canada 


\section{Introduction}

People value being paid appropriately for their work-but many working adults report a discrepancy between what they earn and what they think is fair. As Jasso (1978, p. 1399) observed decades ago: "We live in a world that rarely realizes congruence between actual earnings and just earnings." Data from the 2017 Canadian Work, Stress, and Health Study show that 52 percent of Canadian workers report being paid less than what is just (Narisada, 2019), and similar statistics have been documented in the United States and beyond (ISSP Research Group, 2012). This perception of underreward has consequences for employee health and well-being (Colquitt et al., 2001; Robbins et al., 2012), including job dissatisfaction (Narisada \& Schieman, 2016), depressive symptoms (Tepper, 2001), and poor physical health (Schunck et al., 2015). These findings underscore the importance of understanding the processes that shape the sense of underreward. More specifically, it encourages researchers to continue examining a key question in distributive justice: What do people think is just?

Our objective is to elaborate on the nature of work-related contributions and needs that shape workers' sense of their just reward-that is, what individuals think they should justly earn. By expanding the scope of what constitutes contributions and needs for contemporary workers, we can better understand how individuals come to perceive their earnings as unjust. We address this objective by employing a mixed methods design that consists of a qualitative analysis of focus groups and a follow-up quantitative analysis of a national survey of workers. We adopt this approach to discover previously underexplored determinants of the just reward, generate testable hypotheses, and evaluate those hypotheses with a random sample that allows generality of patterns to the broader population. In this endeavor, we respond to recent recommendations in the sociological justice literature for greater integration of insights from qualitative research with those from surveys and experiments (Kittel, 2020). We report and interpret evidence from three focus group interviews of 22 workers from the Greater Toronto Area in Ontario, Canada. These interviews reveal two factors that elevate workers' just reward and contribute to their sense of underreward: (1) "downloaded" and "sideloaded" extra work and the associated sense of overload, and (2) rising costs of living and the corresponding financial strain. We then operationalize these concepts and test our hypotheses using data from a nationally representative sample of 2,111 workers known as the 2019 Canadian Quality of Work and Economic Life Study (C-QWELS).

\section{Background}

\section{The Equity Principle and Work-Related Contributions}

Individuals perceive a sense of justice when the amount of reward received corresponds to the amount regarded as just based on distributive justice principles 
(Hegtvedt, 2018). Using terminology from Jasso's distributive justice theory, an observer compares the actual reward (reward received) to the just reward (reward regarded as just) to produce a justice evaluation, an evaluation of whether the recipient has been rewarded fairly, and if not, the severity of underreward or overreward (for a recent review, see Jasso et al., 2016). As the just reward serves as the basis by which the actual reward is evaluated, the specification of factors that shape the just reward is central to understanding how individuals perceive underreward. Scholars have identified three main distributive justice principles that guide decisions about the just reward: The equality principle dictates that all recipients should earn the same amount of reward, the equity principle dictates that reward should be distributed based on recipients' inputs, and the needs principle dictates that reward should be distributed based on recipients' needs (e.g., Deutsch, 1975).

Which principles guide evaluations about the fairness of earnings? Factorial survey research has examined this question using vignette designs, where observers are presented with descriptions of fictitious persons and are tasked with either providing justice evaluations of the actual earnings or the amount of just earnings (Alves \& Rossi, 1978; Auspurg et al., 2017; Gatskova, 2013; Hermkens \& Boerman, 1989; Jasso \& Rossi, 1977; Shamon \& Dülmer, 2014; for a review, see Liebig et al., 2015). Studies consistently show that observers do not regard equality of earnings as fair. Rather, equity and need principles underlie observers' evaluations, with the former being particularly salient. With regard to the equity principle, observers tend to evaluate vignettes with greater inputs-most importantly, occupational prestige and educational attainment-as more underrewarded and deserving a higher just reward (e.g., Alves \& Rossi, 1978; Hermkens \& Boerman, 1989; Shamon \& Dülmer, 2014). However, the types of inputs assessed tend to focus on individual attributes like occupational prestige (Cook \& Yamagishi, 1983), while inputs that are readily conceived as work-related contributions have been limited to general indicators of "effort" or "job performance" without further specification. For example, work effort may represent time spent at work, the intensity at which one works, and so on-but the meaning of effort is obscured when vignettes are presented as simply signaling actors' low versus high effort. In sum, factorial survey studies demonstrate the existence of a normative structure that guides judgments about the fairness of earnings, and the equity principle appears to be central; however, the specific nature of work-related contributions assessed in these designs have been somewhat restricted. ${ }^{1}$

Contributions may encompass dimensions of effort, ability, and performance (see Törnblom \& Kazemi, 2012). Following Adams' (1963) emphasis on effort as a key input, dimensions of effort appear prominently in prior conceptualizations of workrelated contributions. Studies that assess fairness perceptions of workers' own earnings find that those with longer contractual working hours and overtime hours report

\footnotetext{
1 We acknowledge that vignettes with a large number of dimensions can present challenges for observers who are tasked with rating them and this can create methodological issues (Auspurg \& Hinz 2015). It is therefore understandable that factorial survey studies have focused on these general indicators of work contributions.
} 
higher levels of underreward (Liebig et al., 2012; Sauer \& May, 2017; Valet, 2018). While work hours represents an important aspect of effort, work effort can be conceptualized more broadly as exposure to work demands that necessitate high investment in the work role. This is particularly evident in occupational stress frameworks such as the effort-reward imbalance (ERI) model, which stipulates that "failed reciprocity" in employer-employee relationships marked by high effort-low reward conditions undermine employee health (Siegrist, 1996; for a review, see van Vegchel et al., 2005). In this model, effort is measured across six dimensions: physical load, time pressure, overtime hours, work interruptions, responsibility, and increased demands over time (Siegrist et al., 2004). The ERI model does not measure justice perceptions, as the imbalance between effort and reward is assumed to directly affect health. However, the ERI model's conceptualization of effort is clearly aligned with the notion of inputs in distributive justice. Beyond studies in the ERI tradition, applications of the job demands-resources (JD-R) model (Bakker \& Demerouti, 2017) to perceived inequity suggest similar conceptualizations of work effort. For example, Hu et al. (2013) demonstrate that job demands-which comprise a broad set of demands like interpersonal conflict in addition to workload-harm employee well-being, partly through the perception of under-benefit in the employer-employee relationship. Taken together, these ideas and findings indicate that the elements of work effort that are relevant to justice perceptions include work hours, but also exposure to work demands.

These perspectives have been applied and extended in recent population-based research that directly assess the fairness perceptions of earnings. For example, Sauer and May (2017) report higher just earnings among workers exposed to poor social relationships at work, a type of demand in the conceptual frame of the JD-R model. Another study finds that work pressure is associated with higher just earnings-in part because work pressure increases blurred boundaries between work and family roles and greater work-family conflict (Narisada, 2020). In the present study, we build upon this research by extending the conceptualization of work effort among contemporary workers, asking: How do workers make sense of their efforts and how are they related to their expectations of rewards? As we demonstrate below, the themes discovered from the focus group interviews shed light on previously underexplored forms and processes of work effort that elevate workers' reward expectations and contribute to their sense of underreward.

\section{The Need Principle and Financial Circumstances}

In contrast to the equity principle, the need principle dictates that outcomes should be distributed based on recipients' needs (Deutsch, 1975). In early experiments on the need principle, two hypothetical persons were described as having completed a joint task with equal inputs but varying in financial need. Subjects tended to allocate a larger portion of the reward to the person with greater need-indicating that need is a standard that guides decisions about what people should justly receive (Lamm \& Schwinger, 1980, 1983). Likewise, factorial surveys show that people use the need principle to evaluate fairness in the distributions of earnings: All else being 
equal, observers tend to rate actors in vignettes who are married or have children as more underrewarded and deserving higher earnings (Alves \& Rossi, 1978; Gatskova, 2013; Jasso \& Rossi, 1977; Shamon \& Dülmer, 2014). These characteristics that represent greater need, however, are less strongly associated with justice evaluations or just earnings compared to dimensions like occupational prestige or education (e.g., Hermkens \& Boerman, 1989; Shamon \& Dülmer, 2014). Thus, there appears to be a consensus that the need principle is given less weight than the equity principle in guiding fairness evaluations of earnings (Liebig et al., 2015). Supporting these observations, cross-national (non-factorial) surveys on justice attitudes indicate that while the majority of individuals support income distributions based on effort and performance (e.g., how "hard" and how "well" people work), there is less support for distributions based on need (e.g., "what is needed to support a family" and the presence of children) (Evans et al., 2010; see also Aalberg, 2003).

The aforementioned studies demonstrate that people do consider need as a standard in evaluating how earnings should be distributed, although it appears to be less salient than the equity principle. However, to our knowledge the ways that need considerations shape evaluations of workers' own earnings remains relatively underexamined. One question that emerges from the findings in factorial survey research is whether need can be assessed in more direct ways. It can be argued that marital and parental statuses - as depicted in the vignettes - are proxies of need. That is, the relevance of these factors is interpreted as supporting the operation of the need principle-presumably because married individuals and those with children are likely to have greater financial need. We therefore extend previous research with a more direct examination of financial circumstances and assess how these are related to fairness evaluations of one's own earnings. This consideration is important in light of Kittel's (2020:103) conceptualization of need-based justice, which entails "the idea that all members of a society are entitled to the consumption of a certain basket of goods, or put otherwise, a certain standard of living." We seek to assess that standard of living and the sense of need surrounding it by advancing understanding about the nature and relevance of need in workers' accounts of unjust earnings.

\section{Methodological Overview}

The present study employs a mixed methods research design by drawing on focus group interviews among Toronto residents and survey data from a national sample of Canadian workers. Our motivation for employing two sources of data is complementarity, whereby the results from one method is used to elaborate, enhance, and interpret the results from another method (Greene et al., 1989; Small, 2011). We base our approach on Morgan's (2014) sequential-priorities model, which consist of four general mixed methods research designs that differ in the principles of sequencing and prioritizing. The present study falls into the category of a principal qualitative project with a quantitative follow-up (QUAL $\rightarrow$ quant). We analyzed our focus group data to identify themes deductively based on our research questions and inductively through interview responses to generate testable hypotheses about the factors that shape expectations for greater rewards. We then operationalize the 
concepts identified in the focus groups with survey items and test our hypotheses deductively using a random sample of workers. The quantitative follow-up extends a standalone qualitative project by permitting researchers to assess whether the experiences among a specific group of individuals can be generalized beyond this context to the broader population (Morgan, 2014). We first discuss the findings from the focus group and the hypotheses that they generate. This is followed by the discussion of the findings from the quantitative analysis.

\section{Focus Group Interviews of Toronto Workers}

\section{Data}

We conducted three focus group interviews between July and September of 2018 with the objective of discovering the nature of working conditions that contribute to perceptions of underreward. Focus groups are appropriate for examining the ways people make sense of their own experiences and how these thoughts are clarified through interaction in a group discussion (Krueger \& Casey, 2014). All participants had previously taken part in the 2017 Canadian Work, Stress, and Health survey (CANWSH), a national telephone survey of Canadian workers. From this dataset, we recruited 22 participants residing in the Greater Toronto Area who reported being underrewarded on at least one of three survey questions on distributive justice (reported in Appendix Table 3). Each focus group consisted of 6-9 participants, with each interview lasting about 90 minutes. While this sample is not meant to be representative of the broader population of workers, our participants were diverse with respect to demographic characteristics. We report the profiles of the participants in Appendix Table 4.

To facilitate group interviews, the CANWSH survey questions on distributive justice were used as a guide to foster discussion and engagement among the participants. After the completion of the interviews, each participant received an incentive of $\$ 70$. We audio recorded the interviews and transcribed them verbatim. We used NVIVO to assist our analysis of data. Nodes were used to code the transcripts, which were organized into node hierarchies that represent particular themes. After coding the transcripts separately, the authors of the study met to discuss emerging themes and interpretations of participants' responses and exchanges. All names that appear in the findings are pseudonyms.

\section{Findings}

Our analysis of the focus group data reveals two key themes that shape higher just reward, and in turn, evaluations of underreward. The first pertains to work-related effort: Extra work-which can be "downloaded" from superiors or "sideloaded" from colleagues - contributes to feelings of being overloaded. The second pertains to the elements of need: Rising cost of living and the induced financial strain. In 
addition to these themes, a sub-theme emerged regarding combinations of contributions and need. We discuss each of these below.

Extra Work I: Downloaded Work. The first theme pertains to the ways in which employees are required to complete extra or additional work-work that is perceived to extend beyond the parameters of the job description. One form of extra work emerges when additional accountabilities and responsibilities are "downloaded" to subordinates from those in more senior positions or with greater job authority. When the moderator asked focus group participants to reflect on their responses to the first distributive justice item (DJ1 in Appendix Table 3), Chris, a male disabilitysupport worker explained:

Chris: I just find that the workload has increased over the years.

Moderator: The workload?

Chris: Yeah, the workload. You know, more accountability measures have been downloaded from senior positions, another position above you has been downloaded below. And yet, you know, you don't see that increase [in pay] per se. I can say we are fortunate in a way that we are protected by a unionized environment, in some sense. But, it doesn't stop certain policies, you know, changing and interrupting your work flow, flow each time.

Chris then elaborated on what he means by "accountability measures":

Chris: We are required to teach and give personal services to individuals that need support. But we are also required to document individual progress and all that. And documentation changes over time, so you know, that personal oneon-one teaching is being taken away into a documentation process. So your workflow that you are used to gets interrupted by a new policy, a new kind of documentation, etcetera.

Moderator: So [...] the reason why you reported that you feel underpaid is what? Related to...?

Chris: Yeah, related to the additional work.

Chris identifies the additional work - the downloaded accountability measuresas a source of his evaluation of underreward. New policies implemented by management generate new burdens associated with additional documentation that, in turn, interrupts his workflow. This downloaded work detracts from his ability to engage in the primary aspects of his job-the activities related to one-on-one teaching of individuals with disabilities. The equity principle predicts that this kind of extra work represents a type of contribution that should translate into higher rewards; however, as Chris lamented, there is no commensurate increase in his pay-and this shapes his expressed evaluation of underreward.

The concerns raised by Chris resonated with other focus group participants, who subsequently shared their experiences with this theme, adding elaborations to the origins and nature of downloaded work:

Madeline: It's like what [Chris] mentioned too...It's like the more heads of the departments they get rid of, the more it comes down to you. So, we used to have people that do this, so now we want you to look after that, and continue 
what you're doing. It gets to be more and more and more, so we'll have less people, and then everybody is just a number basically working away trying to keep their head above water.

Candace: And then, they don't want to give you the job title name, because they don't want to pay you, so they just make you do the job and you don't have the job title...The same job as the supervisor or somebody getting more money, and then they're not paying you for that.

Jack: I was just going to agree with [Madeline] on that [...] I get multiple extra responsibilities, basically: "We don't need more people. We need you to do more."

When senior positions are dissolved, the responsibilities of those positions are downloaded to remaining workers. Thus, in addition to the extra work associated with new documentation processes that Chris identified, downloaded work also encompasses work that superiors should be or had been doing that are passed on to subordinates. This extra work must be completed on top of their regular responsibilities and without additional resources to meet those demands, which in Madeline's case contributes to the sense of being overwhelmed. This narrative resonates with Kelly and Moen's (2020) recent analysis of overload, "the sense that there is too much to do given the resources at hand" (p.59), an increasingly prevalent issue among contemporary workers. Financial pressures to cut costs often steer organizations to downsize or offshore labor abroad. This leads existing workers to do more work with less, contributing to the sense of overload that has consequences for employee performance, retention, and well-being (Kelly \& Moen, 2020).

This exchange also intersects with Pearlin's $(1983,1989)$ idea of role restructuring whereby workers recognize an expansion in their usual work-related responsibilities, which can result in "the violation of expectations" (Pearlin, 1989:246). These violated expectations about one's scope of work responsibilities could lead workers to re-evaluate their pay. Furthermore, Candace's experience suggests elements of exploitation and devaluation, as she does not receive an increase in status or pay that should be associated with taking on more responsibilities and conducting the same tasks as higher-paid supervisors. In distributive justice terms, we can surmise that organizational restructuring increases exposure to downloaded work, which elevate workers' just reward-but actual earnings and other perceived rewards like higher status are fixed. This discrepancy shapes the evaluation of underreward.

Extra Work II: Sideloaded Work. Another form of extra work pertains to the ways in which work is "sideloaded" from coworkers or peers in work groups. In contrast to the top-down nature of downloaded work, sideloaded work represents a lateral movement of extra work demands. First, sideloaded work can emerge when those who are especially skilled in their jobs have to attend to mistakes or difficulties incurred by their colleagues. Rosa, a female beautician, explained:

Rosa: I felt like my skills, they recognized that they were higher than some of the coworkers so they would make me fix some issues, or clients were unsatisfied, so they would give them to me so I can fix it [...] And they also don't pay you more for having to fix other people's problems [...] Because I can do it, so they give it to me. That's why I guess it feels unfair. 
Fixing coworkers' problems is extra work that should be associated with greater pay-but Rosa's pay did not reflect her contributions, shaping her sense of underreward. While her skills may signal higher status relative to her other colleagues, Rosa's experience suggests a potential cost of being perceived as more competent than coworkers: This can be a source for receiving sideloaded work that may not come with commensurate increases in pay.

Sideloaded work also emerges from other means. The respondents identified employee turnover as another source of sideloaded work, as demonstrated in the following exchange:

Jack: [Referring to his employer] So they're trying to get the people who will take the absolute minimum, because they have no experience, and work tons and tons of hours, because they want the experience, and get treated like, well, a cog in the machine. And so the turnover rate is very high. Not necessarily because they don't necessarily like some of the stuff they're doing, but it's because it's, well...

Candace: It's going nowhere.

Jack: Going nowhere.

Emma: Yeah, the turnover is huge.

Candace: They stay in, they get the experience [Jack: That's right]. Like, one time in the lab, there's lot of students that came out of university and they know that they should be making more money [...] and once they gain 6 months experience, they were gone. And about 6 people they hired during that time, and everyone just left.

Jack: And then if you're one of the people that's still there, then you have to do all the other people's work until they maybe hire some other people to replace them.

This exchange suggests that employee turnover creates extra work that is sideloaded to workers who remain. Employees may leave the organization in part due to the demands of work in combination with feeling devalued, and this turnover leads to more demands on the remaining employees. In turn, this may shape the remaining workers' perceptions of underreward, which as prior research demonstrates, is associated with turnover intentions and enacted turnover (D'Ambrosio et al., 2018; George \& Wallio, 2017; Geurts et al., 1999). While employee turnover is often examined as an outcome of perceived injustice, these responses suggest another possibility: The turnover behavior of other employees can be a potential antecedent of justice perceptions through the creation of sideloaded work for those workers who remain at the job.

Collectively, these interview responses generate hypotheses that can be assessed in a broader sample of workers. First, extra work that is either downloaded from superiors or sideloaded from coworkers and peers should be associated with higher reward expectations. Second, this relationship should, in part, be due to the ways that extra work increases the quantity of work that contributes to a sense of overload. Based on these themes, we test the following: 
Hypothesis 1 Higher levels of extra work should be associated with higher expectations of rewards.

Hypothesis 1A Higher levels of job pressure should partly explain the relationship between extra work and higher expectation of rewards.

Rising Cost of Living and Financial Strain. Beyond the equity principle and extra work, the interviews also revealed a theme regarding the rising cost of living and induced financial strain. The focus group participants directly noted an expectation of correspondence between the cost of living and earnings. For instance:

Karan: [...] the point of reference for me is the cost of living, like it keeps changing. Like for example, say the mortgage rate goes up couple of years later. I would feel terribly underpaid because I can't meet my expenses.

In another exchange, when the moderator asked participants to reflect on factors that contribute to feeling paid "less than just" (DJ2 in Appendix Table 4) the following discussion unfolded:

Jack: So, would you include in here the "Toronto bubble" in terms of some salaries and things being higher than in other areas... as affecting people's pay grade for skill? Because I'll just put it... I haven't worked in Toronto for more than a year, but it's costing me more, it's costing everything more to work in Toronto, but there is no equivalent change there.

Moderator: In the pay?

Jack: In the pay.

Moderator: So, by the "Toronto bubble," what do you mean by that?

Jack: Well the people tend to... there's usually higher wages because there's higher costs. I don't know if that's the case every... anymore.

Madeline: Not anymore. Back in the day, but not anymore.

Jack's statement that "there's usually higher wages because there's higher costs" invokes the need principle, which stipulates that rewards should be distributed according to what people need-or at least their perception of it. Jack recognizes that there are higher costs associated with living in an urban area like Toronto compared to other less-urban areas, and that wages should reflect these costs. Madeline's response suggests that wages aligned more closely with the cost of living in the past—but that this is not the case today. Higher costs should correspond with higher earnings, so we probed on what these costs entail. The participants elaborated:

Emma: [...] Go right to Barrie, look at rent [Madeline: Yup!], I was looking at Aurora rents the other day [Akhil: Yeah, that's right], and they're like \$1600.

Moderator: So your sense is that, that underlying dynamic makes these questions about pay even maybe more...

Madeline: Yes! Cost of living has just nothing to do with what you're getting paid.

Akhil: I'm trying to catch up about 40 years with the inflation [some laugh]. I can't. When I moved to Canada, gas was 40 cents a liter. Today, it's $\$ 1.30$. 
Emma: Jobs aren't getting a 2\% raise every year. It's not being factored in. It's not.

Madeline: It's not even a question where we work. Nobody even gets one anymore. And I thought really?

Jack: Like I haven't gotten a raise, and my commute distance has doubled. [Emma: Gas!]. So gas and everything has gone up [Emma: Insurance!]. I'm making less just because I'm paying more in gas [Madeline: Yeah., Chris: Yeah, it's the same].

Rising costs associated with rent, inflation, and commuting means that higher earnings are necessary to meet basic needs. Rising costs of living - and the associated financial strain-contribute to a greater expectation of rewards. While it was unclear from the responses whether participants expected their employers to be responsible for allocating rewards based on these needs, it is clear that individuals do desire an adequate degree of correspondence between their earnings and the rising cost of living. These narratives contribute to the following hypotheses:

Hypothesis 2 The perception that the cost of living have increased should be associated with a higher expectation of rewards.

Hypothesis 2A Financial strain should partly explain the relationship between cost of living and higher expectation of rewards.

The combination of contributions and needs. Some focus group participants interwove experiences about contributions and need, which suggest that elements of work contributions and need may combine to shape reward expectations. For example, Katie, a contract faculty member identified a large pay gap between herself and tenured faculty and described how her work demands spill over beyond the boundaries of the classroom and the scope of compensation:

Katie: They would like me to go to meetings if I'm available and things like that. I don't get paid for that kind of stuff. It's in the theatre department, so they don't say you must spend your evenings seeing these shows, but because they are my students so I feel obliged to see them. I don't get paid for that. So, I do a ton of outside work, I mean outside the hours that I spend in the classroom.

Katie then describes a conversation between two women that she overheard on a subway on her way to the focus group:

Katie: "Why did you decide to go into law?" This is interesting, and she said: "Well, I started off, I went back and got my Masters. I started to teach in continuing education [at a university]. You know, a lot of teachers I was working with were just saying 'We make no money. We can't even afford to buy a car.," So she said "So I decided to write my LSATs." And then I mean [laughs], she's never looked back. But it was interesting for me to eavesdrop on that because I thought you were absolutely right there. You can't even afford to buy a car. You know, I work, I'm up at [a university] 4 days a week. I'm not teach- 
ing all day, but when I'm not, I'm juggling other jobs and I'm also taking a ton of work home that I don't get paid for and, you know, it goes on.

Katie's response suggests that concerns about extra work, overload, and financial need shape greater reward expectations. She engages in additional work that is not compensated; at the same time, she evokes the need principle as she mentions, "You can't even afford to buy a car." This represents a standard of living she feels entitled to (Kittel, 2020). Katie's narrative suggests two possibilities: One is that elements of contributions and need have independent effects on reward expectations. Another is that these factors also interact to shape even greater expectation of rewards. That is, concerns about need may exacerbate the felt injustice associated with work contributions. With these ideas in mind, we test the following:

Hypothesis 3 The effects of extra work and job pressure on reward expectations should be stronger among those who perceive higher cost of living and financial strain.

As detailed above, the focus groups generated rich narratives and testable themes about the sources of perceived underreward. We now turn to the quantitative component of this study to assess whether these detected patterns generalize beyond this specific group of workers to the broader Canadian working population.

\section{National Survey of Canadian Workers}

\section{Sample}

We test our hypotheses with data from the 2019 Canadian Quality of Work and Economic Life Study (C-QWELS), a nationally representative survey of Canadian workers. Respondents are members of the Angus Reid Forum, an online panel of about 65,000 respondents built and managed by Angus Reid Inc (www.angusreid. org). A random sample of 2,524 workers was selected from this panel and asked to participate in the survey (42\% response rate). ${ }^{2}$ The survey includes questions about work effort and need that we constructed based on the responses from the focus group interviews. The results were weighted by age, gender, education, and region based on distributions of the 2016 Canadian Census data to ensure representativeness. We excluded business owners and self-employed workers from our

\footnotetext{
2 The Angus Reid Forum contains enough people in each major demographic group to draw randomized samples that represent the population as a whole. To ensure that participants represents the public in terms of demographics and attitudes, surveys are based upon representative samples from each panel that are randomized and statistically weighted according to the most current demographic and regional voting data available. In the case of C-QWELS, sample selection started with creating a balanced sample matrix of the Canadian population. A randomized sample of Angus Reid Forum members are then selected to match this matrix to ensure a representative sample. Subsequent to this step, final sample data is analyzed and weighted to a series of variables (age, gender, region, 2015 Federal Election voting behavior) to ensure balanced representativeness of all working Canadians.
} 
analysis as these workers have more latitude in setting their own earnings compared to those who work for an employer (e.g., Schunck et al., 2015). Missing values were addressed using multiple imputation with 100 replications. The final analytical sample consists of 2,111 workers.

\section{Measures}

Justice Evaluation We use the following item to measure workers' justice evaluation of earnings: "When you think about the pay you get for your job, do you feel your pay is unfairly low, unfairly high, or is it a fair amount?" We coded this measure so that higher values indicate more underreward: -5 (Unfairly high) to +5 (Unfairly low) with 0 indicating "a fair amount." A similar item has been assessed in a national survey of German workers and reported in recently published research (Sauer \& May, 2017; Schneider \& Valet, 2017). The mean justice evaluation is $.866(\mathrm{SD}=2.059)$. Thus, on average, respondents reported to be slightly underrewarded - consistent with other recent data from workers in Canada (Narisada, 2020) and Germany (Sauer \& May, 2017; Valet, 2018).

Extra Work Based on the responses from focus group participants, we constructed three items to measure extra work that is downloaded or sideloaded: "I am expected to do things that go beyond my job description or duties," "Sometimes it feels like responsibilities are downloaded from those in more senior positions," and "I have to do extra work because of the lack of effort or mistakes from others." The response choices are coded as (1) "strongly disagree," (2) "somewhat disagree," (3) "somewhat agree," and (4) "strongly agree." We averaged the items to create the extra work index (alpha $=.63)$.

Job Pressure We use the following items that refer to the last three months: "How often did you feel overwhelmed by how much you had to do at work?" "How often did you have to work on too many tasks at the same time?" and "How often did the demands of your job exceed the time you have to do the work?" The response choices are coded as: (1) "never," (2) "rarely," (3) "sometimes," (4) "often," and (5) "very often." We averaged the items to create a job pressure index (alpha $=.88)$.

Cost of Living We use the following item to assess the subjective evaluation of cost of living: "How has your experience of the cost of living changed during the past few years?" The response choices are coded as: (1) "gotten much better," (2) "gotten somewhat better," (3) "stayed the same," (4) "gotten somewhat worse," and (5) gotten much worse."

Financial Strain We use the following three items to assess financial strain. The first two items ask: "How often in the past year did you not have enough money to buy clothes or other things that your household needed?" and "How often in the past year did you have trouble paying the bills?" The response choices are coded as (1) "never," (2) "rarely," (3) "sometimes," (4) "often" and (5) "very often." The third item asks: "How do your finances usually work out by the end of the month?" The response choices are coded as (1) "a lot of money left over," (2) "a little money left over," (3) "just enough to make ends meet," (4) "barely enough to get by," and (5) 
"not enough to make ends meet." We averaged the items to create a financial strain index (alpha =.85).

Control Variables We control for social and economic statuses and working arrangements as these may be associated with dimensions of effort, need, and the justice evaluation. Education is coded (1) some elementary or high school, (2) high school graduate, (3) some college/trade school, (4) graduate from college/trade school, (5) some university, (6) university undergraduate degree, and (7) university graduate degree. Personal income is measured as personal income before tax in 2018. We use the natural log of personal income in our analyses. Occupation is coded (1) higher administrative, (2) professional and technical, (3) clerical, (4) sales, (5) service, (6) skilled worker, (7) semi-skilled worker, (8) unskilled worker, and (9) other. Work hours per week is coded (1) fewer than 30 hours, (2) 30 to 39 hours, (3) 40 to 49 hours, and (4) 50+ hours. Work contract is coded (0) full-time and (1) part-time. Work sector is coded (1) for-profit, (2) government, and (3) non-profit. Demographic controls include gender $(0=$ men, $1=$ women, $2=$ non-binary $)$, visible minority status $(0=$ not a visible minority, $1=$ visible minority), marital status $(0=$ not married, $1=$ married), number of children under 18 living at home, age (in years), and region of residence. Table 1 reports the weighted descriptive statistics for all study variables.

\section{Plan of Analysis}

We test our hypotheses in Table 2 using OLS regression techniques. We first examine how dimensions of contributions are associated with the justice evaluation. Model 1 tests Hypothesis 1 by examining the relationship between extra work and the justice evaluation, net of personal income and other controls. In Model 2, we test Hypothesis $1 \mathrm{~A}$ by adding job pressure and examining whether the addition of job pressure reduces the coefficient for the association between extra work and the justice evaluation. Following recommendations by MacKinnon (2008), we also test for mediation directly with Sobel tests. The test is derived by multiplying (a) the coefficient of the association between extra work and job pressure and (b) the coefficient of the association between job pressure and the justice evaluation, and then dividing the product by its joint standard error.

We then assess how dimensions of need are associated with the justice evaluation. Model 3 tests Hypothesis 2 by adding cost of living. In Model 4, we test Hypothesis $2 \mathrm{~A}$ by adding financial strain and examining whether the inclusion of financial strain reduces the coefficient for cost of living on the justice evaluation. Like our analysis for job pressure, we use the Sobel test to directly test whether financial strain functions as a mediator. Subsequent models test Hypothesis 3 by including the following interaction terms: Extra work $\times$ Cost of living, Extra work $\times$ Financial strain, Job pressure $\times$ Cost of living, and Job pressure $\times$ Financial strain.

It is important to note that our analysis examines the effects of extra work, job pressure, cost of living, and financial strain on the justice evaluation-net of personal income. Distributive justice theory stipulates that the comparison between the just reward and the actual reward produces the justice evaluation. Given this 
Table 1 Weighted descriptive statistics

\begin{tabular}{|c|c|c|}
\hline & Mean or proportion & SD \\
\hline Justice evaluation & .87 & 2.06 \\
\hline Extra work & 2.57 & .76 \\
\hline Pressure & 3.24 & 1.07 \\
\hline Cost of living & 3.73 & 1.05 \\
\hline Financial Strain & 2.31 & 1.05 \\
\hline Personal income & $63,625.22$ & $41,052.01$ \\
\hline Education & 4.91 & 1.56 \\
\hline \multicolumn{3}{|l|}{ Work hours } \\
\hline$<30$ hours/week & .16 & \\
\hline 30-39 hours/week & .35 & \\
\hline 40-49 hours/week & .39 & \\
\hline $50+$ hours/week & .11 & \\
\hline Full-time & .81 & \\
\hline \multicolumn{3}{|l|}{ Sector } \\
\hline Private & .54 & \\
\hline Government & .36 & \\
\hline Non-profit & .11 & \\
\hline \multicolumn{3}{|l|}{ Occupation } \\
\hline Higher admin & .08 & \\
\hline Professional & .35 & \\
\hline Clerical & .18 & \\
\hline Sales & .09 & \\
\hline Service & .11 & \\
\hline Skilled & .08 & \\
\hline Semi-Skilled & .06 & \\
\hline Unskilled/Farming & .06 & \\
\hline \multicolumn{3}{|l|}{ Gender } \\
\hline Men & .51 & \\
\hline Women & .49 & \\
\hline Non-binary & .01 & \\
\hline Visible minority & .13 & \\
\hline Age & 40.43 & 13.21 \\
\hline Married & .57 & \\
\hline Number of children at home & .59 & .98 \\
\hline \multicolumn{3}{|l|}{ Region } \\
\hline British Columbia & .13 & \\
\hline Alberta & .12 & \\
\hline Saskatchewan & .03 & \\
\hline Manitoba & .04 & \\
\hline Ontario & .38 & \\
\hline Quebec & .24 & \\
\hline Atlantic Canada & .07 & \\
\hline
\end{tabular}


Table 2 Justice evaluation regressed on elements of effort and need, interactions, and controls $(N=2,111)$

\begin{tabular}{|c|c|c|c|c|c|}
\hline & Model 1 & Model 2 & Model 3 & Model 4 & Model 5 \\
\hline \multicolumn{6}{|l|}{ Focal variables } \\
\hline Extra work & $.511^{* * *} *$ & $.298 * * *$ & $.263 * * *$ & $.255 * * *$ & -.039 \\
\hline Job pressure & & $.299 * * *$ & $.255 * * *$ & $.217 * * *$ & $.214^{* * *}$ \\
\hline Cost of living & & & $.284 * * *$ & $.225^{* * *}$ & $.221 * * *$ \\
\hline Financial strain & & & & $.215 * * *$ & -.124 \\
\hline Extra work $\times$ Fin. strain & & & & & $.128 *$ \\
\hline \multicolumn{6}{|l|}{ Controls } \\
\hline Personal income (ln) & $-.438 * * *$ & $-.439 * * *$ & $-.428 * * *$ & $-.359 * * *$ & $-.362 * * *$ \\
\hline Education & -.037 & -.034 & -.020 & .001 & -.002 \\
\hline \multicolumn{6}{|l|}{ Work hours } \\
\hline$<30$ hours $^{\text {a }}$ & -.388 & -.287 & -.262 & -.246 & -.243 \\
\hline 30-39 hours ${ }^{a}$ & -.046 & -.005 & -.015 & -.038 & -.042 \\
\hline $50+$ hours $^{\text {a }}$ & .056 & -.036 & -.042 & -.057 & -.051 \\
\hline Part time ${ }^{b}$ & .189 & .192 & .150 & .172 & .157 \\
\hline \multicolumn{6}{|l|}{ Sector } \\
\hline Government ${ }^{\mathrm{c}}$ & $-.263^{*}$ & $-.265^{*}$ & $-.288 * *$ & $-.289 * *$ & $-.290 * *$ \\
\hline Non-profit ${ }^{c}$ & -.165 & -.175 & -.165 & -.156 & -.168 \\
\hline \multicolumn{6}{|l|}{ Occupation } \\
\hline Professional $^{\mathrm{d}}$ & $.574 * *$ & $.551 * *$ & $.511 * *$ & $.500 * *$ & $.488 * *$ \\
\hline Clerical $^{\mathrm{d}}$ & $.430^{*}$ & $.508^{*}$ & $.481 *$ & $.442 *$ & $.407^{*}$ \\
\hline Sales $^{\mathrm{d}}$ & $.646^{* *}$ & $.691 * *$ & $.630 * *$ & $.585^{*}$ & $.551 *$ \\
\hline Service $^{d}$ & $.726^{* *}$ & $.822 * * *$ & $.783 * * *$ & $.716^{* *}$ & $.705^{* *}$ \\
\hline Skilled $^{\mathrm{d}}$ & $.539^{*}$ & $.652 * *$ & $.563 *$ & $.547^{*}$ & $.506^{*}$ \\
\hline Semi-Skilled $^{\mathrm{d}}$ & $.655^{*}$ & $.796^{* * *}$ & $.726 * *$ & $.705 * *$ & $.680^{*}$ \\
\hline Unskilled/Farming ${ }^{\mathrm{d}}$ & $.996^{* * *}$ & $1.086^{* * *}$ & $1.047 * * *$ & $1.016^{* * *}$ & $1.019 * * *$ \\
\hline Women $^{\mathrm{e}}$ & $.213^{*}$ & .148 & .151 & .138 & .140 \\
\hline Non-binary ${ }^{\mathrm{e}}$ & .244 & .143 & .082 & .017 & .023 \\
\hline Visible minority $=1$ & -.085 & -.114 & -.088 & -.125 & -.115 \\
\hline Age & .007 & .008 & .004 & .004 & .004 \\
\hline Married $=1$ & .095 & .092 & .087 & .121 & .127 \\
\hline Number of children & -.099 & $-.112^{*}$ & $-.128 *$ & $-.143 * *$ & $-.146^{* *}$ \\
\hline \multicolumn{6}{|l|}{ Region } \\
\hline British Columbia $^{\mathrm{f}}$ & .118 & .108 & .095 & .136 & .144 \\
\hline Alberta $^{f}$ & .044 & .033 & -.001 & -.006 & -.009 \\
\hline Saskatchewan ${ }^{\mathrm{f}}$ & -.233 & -.200 & -.276 & -.316 & -.335 \\
\hline Manitoba $^{f}$ & -.072 & -.086 & -.029 & -.084 & -.085 \\
\hline Quebec $^{f}$ & .095 & .071 & .173 & .147 & .149 \\
\hline Atlantic Canada ${ }^{\mathrm{f}}$ & .037 & .038 & .068 & .058 & .054 \\
\hline Constant & 3.656 & 3.188 & 2.346 & 1.406 & 2.264 \\
\hline
\end{tabular}

${ }^{*} p<.05, * * p<.01, * * * p<.001$

Unstandardized regression coefficients shown in table (standard errors are available upon request). Superscripts indicate the following comparisons: ${ }^{\mathrm{a}} 40-49$ hours, ${ }^{\mathrm{b}}$ full-time, ${ }^{\mathrm{c}}$ private sector, ${ }^{\mathrm{d}}$ higher administrative, ${ }^{\mathrm{e}}$ men, ${ }^{\mathrm{f}}$ Ontario 
formulation, Jasso and colleagues (Jasso et al., 2016, p. 208) argue: "For given Actual Reward, the question whether a Rewardee characteristic is associated with the Justice Evaluation is equivalent to the question whether that Rewardee characteristic is associated with the Just Reward." For example, if we observe a positive association between extra work and the justice evaluation in the underreward direction-net of personal income - this indicates that extra work is linked to a higher just reward. This logic guides our decision to regress the justice evaluation on our focal predictors while statistically controlling for personal income.

\section{Results}

In Table 2, Model 1 indicates that extra work is associated positively with the justice evaluation in the underreward direction $(b=.511, p<.001) .{ }^{3}$ Model 2 indicates that job pressure is also positively associated with the justice evaluation in the underreward direction $(b=.299, p<.001)$. The inclusion of job pressure reduces the coefficient for extra work by 42 percent, although it remains statistically significant $(b=.298, p<.001)$. The Sobel test indicates that the indirect effect of extra work on the justice evaluation through job pressure is statistically significant $(Z=5.460$, $p<.001)$. Collectively, these results demonstrate that extra work is associated with greater underreward, in part because extra work is associated with greater job pressure.

Shifting to dimensions of need, Model 3 indicates that the perceived rising cost of living is associated with the justice evaluation in the underreward direction $(b=.284, p<.001)$. In Model 4, financial strain is also positively associated with the justice evaluation in the underreward direction $(b=.215, p<.001)$. The inclusion of financial strain reduces the coefficient for cost of living by 21 percent, although the coefficient remains statistically significant $(b=.225, p<.001)$. The Sobel test indicates that the indirect effect of cost of living on the justice evaluation through financial strain is statistically significant $(Z=3.670, p<.001)$. These results therefore indicate that the perceived rising cost of living is associated with greater underreward, and this is partly explained by financial strain.

In our analyses of interaction effects, Model 5 indicates a significant interaction effect between extra work and financial strain $(b=.128, p<.05)$. For ease of interpretation, Fig. 1 displays the relationship between extra work and the justice evaluation across levels of financial strain. Higher levels of extra work are associated with more underreward-but this relationship is stronger among those who perceive a higher level of financial strain. Separate analyses (not shown) indicate that the three other interaction terms are not statistically significant: Extra work $\times$ Cost of living

\footnotetext{
${ }^{3}$ Some patterns among the control variables are noteworthy. First, we observe that occupying lower occupational classes are associated with the justice evaluation in the underreward direction. This is consistent with prior findings on occupational prestige and the justice evaluation (e.g., Alves \& Rossi, 1978). Compared to employment in the private sector, employment in the government sector is associated with the justice evaluation in the overreward direction. Finally, compared to men, women are more likely to perceive underreward. This difference, however, is explained once we adjust for job pressure (see model 2).
} 


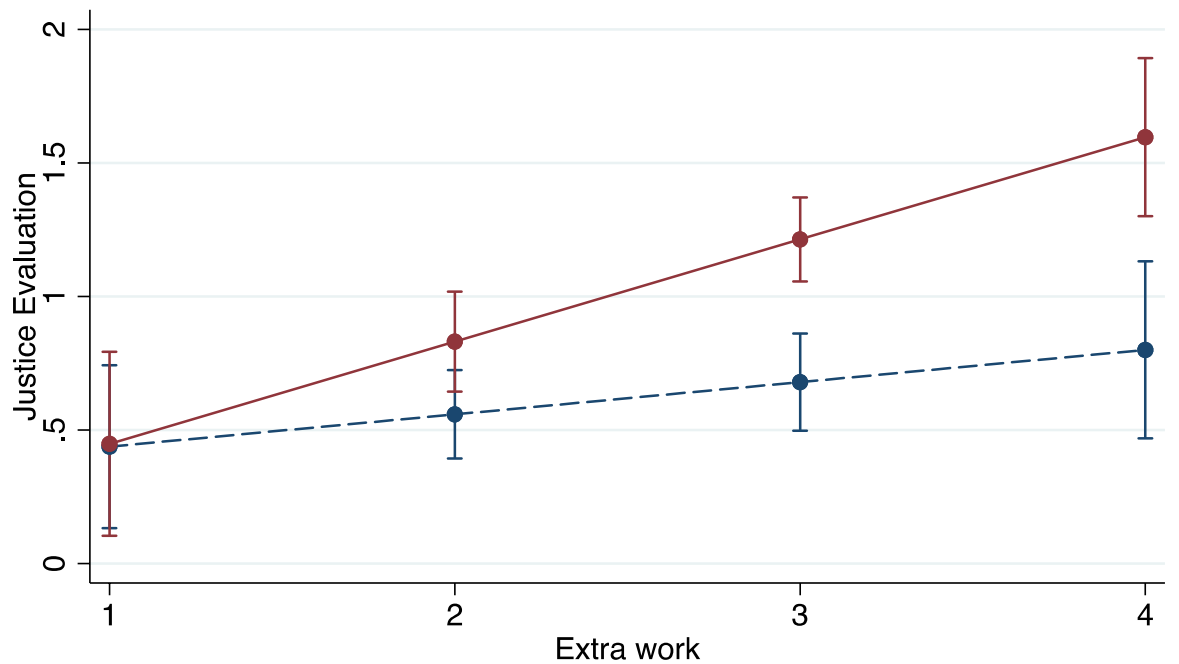

--- Low financial strain (-1SD) —- High financial strain (+1SD)

Note: Predicted values based on Model 5, Table 2

Fig. 1 Extra work and justice evaluation by financial strain

$(b=.104, p=.068)$, Job pressure $\times$ Cost of living $(b=.006, p=.902)$, and Job pressure $\times$ Financial strain $(b=.053, p=.211)$.

As noted earlier, because our models control for personal income, the patterns above can be interpreted as follows: (1) higher levels of extra work, job pressure, cost of living, and financial strain are each positively associated with workers' just reward, (2) job pressure partly mediates the relationship between extra work and the just reward, (3) financial strain partly mediates the relationship between cost of living and the just reward, and (4) financial strain exacerbates the positive association between extra work and the just reward. Collectively, these results support Hypotheses 1, 1A, 2, and 2A, and partially support Hypothesis 3.

\section{Discussion}

A central question in distributive justice is: What do people think is just? It is important to document the answers to this question, especially given the consequences of perceived underreward for employee health and well-being (Clay-Warner et al., 2005; Falk et al., 2018; Narisada, 2017; Schunck et al., 2015; Tepper, 2001). Using a mixed methods research design, our study provides one answer to this question by elaborating on the forms of work-related contributions and needs that shape contemporary workers' sense of their just reward. Our focus group participants shared stories about "downloaded" and "sideloaded" extra work, job pressure, rising costs of living, and financial strain that elevated their expectations for greater rewards and contributed to their sense of being underrewarded. We then operationalized these 
themes and examined whether the patterns may be generalized to the broader population of Canadian workers. Our results demonstrated that each of these factors are independently associated with the just reward while also revealing mediation processes, and there was some evidence that work-related effort and need interact to shape even greater reward expectations. We discuss our main contributions below.

The equity principle is a central distributive justice rule that shapes expectations for greater rewards - and "effort" is a key input that shapes individuals' reward expectations (Adams, 1963). Researchers have measured effort in various ways to examine its association with evaluations about fair earnings. Factorial survey studies have operationalized effort with general measures of effort at work, while studies of reflexive justice evaluations have commonly operationalized effort in terms of working hours. Inspired by research on occupational stress that conceptualize work effort broadly as exposure to work demands (Siegrist et al., 2004), we set out to examine how workers made sense of their work effort and how they were related to their expectations of rewards. Our focus groups highlight the role of extra work and the associated feelings of being overwhelmed as factors that elevate reward expectations. First, extra work can be downloaded from those who hold higher positions of authority. Such work can emerge from organizational restructuring: When senior positions are dissolved, extra work is downloaded to workers below. The nature of downloaded work also entails the type of documentation work that takes away from one's principal and perhaps more gratifying work. Second, extra work can also be sideloaded from coworkers or others who occupy similar levels in the organizational hierarchy. Sideloaded work can emerge when one must take on extra work to correct for colleagues' mistakes or cover for those who are less skilled. One unexpected way in which sideloaded work occurs is through employee turnover. The reduced number of workers lead to more extra work-and completing the work of multiple people can lead to greater reward expectations. Taken together, our interviews document the forms of "extra work" as a novel work-related input and how this shapes the just reward. Given that the participants' narratives also intersected with feelings of devaluation and exploitation-and the implications for workers' sense of self-we encourage future research to examine whether workers' self-esteem and subjective social status may explain the link between extra work and elevated reward expectations.

In addition to the equity principle, prior research indicates that the need principle also guides people's ideas about what individuals should earn (Deutsch, 1975). Prior research using vignettes have documented the relevance of marital and parental statuses in shaping observers' evaluations of what others should earn. We sought to extend this research by directly assessing how workers' own financial circumstances shape evaluations of their own earnings. Our focus group respondents invoked the need principle in discussing their source of perceived underreward. The perception that their earnings have not kept up with increases in the cost of living-and the associated financial strain-contribute to their greater just reward and a sense of underreward. Need-based justice entails the idea that individuals are entitled to a certain standard of living (Kittel, 2020). Our focus group participants suggest that this standard of living entails costs associated with housing, inflation, and commuting - and noted that their earnings should reflect increases in these costs. Prior 
research suggests that need considerations are unlikely to be salient in the work context where relationships tend to be impersonal and the situational goal emphasizes productivity (Deutsch, 1975; Leventhal et al., 1980). While we did not find evidence that workers hold their employers responsible for distributing earnings based on need, it is clear that need considerations do play a role in elevating workers' just reward and shaping workers' sense of underreward.

Though these focus groups generated themes that elaborate on the equity and need principles, these results are limited to a specific group of workers in Toronto. We therefore tested hypotheses generated from the focus groups using a national sample of Canadian workers. Overall, the quantitative results demonstrate that the themes identified in the focus groups generalize to the broader population of working Canadians: Higher levels of extra work, rising cost of living, and financial strain are each associated with greater reward expectations. Our results also indicate processes of work effort and need that were suggested in the focus group narratives. Extra work is associated with a higher just reward, in part, because extra work is associated with higher levels of job pressure. Likewise, the evaluation that the cost of living has gotten worse over the years is associated with a higher just reward, partly because the rising cost of living is associated with financial strain.

The quantitative results also reveal that elements of work effort and need can interact to shape the just reward. Specifically, we found that higher levels of extra work are associated with higher reward expectations-but more strongly for those who report higher financial strain. The particular combination of engaging in uncompensated extra work while being financially strained may implicate a sense of devaluation and injustice that shapes even greater reward expectations. According to the justice judgment model, an individual's judgment of how much of an outcome he or she deserves is an additive function of deserved outcomes based on each distributive justice rule (Leventhal, 1980). Our finding suggests that under some circumstances the judgments of deservingness may be a multiplicative function of distributive justice principles: The amount of reward deserved based on the equity rule may depend on need considerations.

\section{Future Research Directions and Practical Implications}

One direction of future research is to examine the implications of income inequality on fairness evaluations of one's own income. Recent research documents that higher income inequality within one's organization is associated with greater perceptions of unjust pay and a greater just reward (Sauer \& May, 2017). Thus, while social comparisons with coworkers who are similar in age, education, and tasks are a key determinant of fairness perceptions of one's own earnings (Sauer \& May, 2017), comparisons with more privileged members may also be important. Extending this work, future research might assess how income inequality in one's area of residence or the broader society could also shape justice evaluations of one's own earnings. Sachweh's (2012) in-depth qualitative interviews reveal that while Germans generally agree that income differences based on merit is justified, people object to the degree of income inequality-poverty and extreme wealth. In his interviews, participants 
expressed frustrations and psychological strain about their relative socioeconomic inferiority compared to more privileged individuals. In our focus group interviews, a few participants compared their own earnings to those of wealthy CEOs and executives. For example, referencing a CEO that earned "9 million a year," a participant noted that "he makes by lunch time what I make in a year, so that equality has to come" and called on policymakers to "equalize the pay." Higher levels of income inequality in the broader society may be associated with greater perceptions of unjust earnings. If this is true, there are implications for the broader literature on the consequences of income inequality. Prior research has documented a positive association between income inequality and poor well-being (Wilkinson \& Pickett, 2010) and a positive association between perceived unjust earnings and poor well-being (Robbins et al., 2012). Thus, one hypothesis for future research is whether perceptions of unjust earnings could function as a mediator in the association between income inequality and well-being.

Another direction of future research is to assess the impact of the current COVID19 pandemic on work contributions and need. As employers cut costs through layoffs and furloughs, work may have been downloaded, sideloaded, or perhaps even uploaded (from lower to higher status positions) for remaining workers. Moreover, workers may also face increased demands associated with the implementation of COVID-19 health and safety procedures (e.g., performing additional sanitation requirements, managing return-to-work documentation and signage). These forms of extra work that span beyond one's ordinary responsibilities or job descriptions may shape expectations for greater rewards. In addition, as mandates for social distancing forced many white-collar workers to work from home, this flexibility can have downsides. Prior research indicates that schedule control in the face of high work demands can have negative implications for strains in the work-family interface (Badawy \& Schieman, 2020; Blair-Loy, 2009), which are associated with greater expectation of rewards (Narisada, 2020). In the context of high unemployment and increased job and employment insecurity, the flexibility afforded by working from home may increase the pressure to be constantly available to fulfill the "ideal worker" norm-contributing to stress in the work-family interface and the sense of overload. If increases in hours or the quantity of work are not met with adequate recognition from supervisors and management, increased contributions may shape greater perceptions of unjust rewards.

The pandemic also has implications for our findings about need. Unemployment is associated with greater financial strain (Pearlin et al., 1981; Price et al., 2002), which may shape greater perceptions of unjust rewards when returning to work. The economic fallout of the pandemic and the inequalities it has exacerbated may also have implications for the relevance of the need principle in guiding people's decisions about how earnings should be distributed. Recall that need-based justice refers to the idea that "all members of a society are entitled to the consumption of a certain basket of goods, or put otherwise, a certain standard of living" (Kittel, 2020). In practice, the need principle may appear alongside the equity principle by specifying a social minimum from which no one should fall below, and rewards above this minimum are distributed based on merit (Boulding, 1962; Kittel, 2020). Amid the pandemic, a survey from March 2020 indicates that 71 percent of Europeans supported 
the establishment of a universal basic income, where citizens would be paid a fixed amount by the government regardless of employment status (Ash \& Zimmermann, 2020). While prior research has demonstrated that the need principle is not as important as the equity principle in shaping evaluations of what people should earn, the pandemic's economic consequences may have elevated its importance.

We wish to close by reflecting on the practical implications. Organizations should care about their employees' perceptions of underreward. This is evidenced not only by research that documents the effects of underreward on employee health and well-being, but also by studies that demonstrate its association with outcomes that concern organizations, such as absenteeism (de Boer et al., 2002) and turnover (D'Ambrosio et al., 2018). One straightforward implication of our study is that employers may be able to mitigate employee perceptions of underreward by being cognizant of downloaded and sideloaded work and compensating employees for this extra work. Nevertheless, it may not always be feasible to increase monetary rewards for employees. In these circumstances, non-monetary rewards may foster a feeling of recognition that may alleviate concerns about underreward. Our focus group participants provided insights into the ways that these alternative rewards may compensate for the lack of perceived underreward:

Karan: So people most often feel underpaid because they are not being valued in the workplace. Underpaid is not just about money, not in my mind. It's also about the respect you get, also about the value you get at the workplace. It's also about the recognition you get in the workplace. So, the concept of total rewards in my work, it's not just money. It's a whole combination of everything you get at the workplace. So when you miss one of those components, even if you're getting paid enough in terms of dollars, you still feel underpaid. Jane: That's like the compensation thing. You can get paid in a health plan, or you can get paid with your company buying you a car, or you can get paid with your gas being paid because you're self-employed. There are various ways to be compensated [Karan: Yeah]. That aren't cash.

Karan: Also the recognition. You feel...don't you value being recognized for a good job done? Somebody giving you a $\$ 100$ bill and you being recognized in front of others? Which one would you take? I would take the recognition probably...

Susan: I would take the money [laughter].

Steve: Depending on what time of year it is [laughter].

Karan: I mean like, I'm not saying you know all occasions in all situations, but...

Susan: It's important to be valued.

Steve: Every now and then it's always nice to get that pat on the back.

Monetary rewards may be the most desirable form of recognition; however, nonmonetary forms of recognition may also alleviate feelings of underreward. These include benefits as Jane noted-but as Karan emphasized, it can also include more interpersonal forms of recognition such as feeling appreciated for a job well done and an occasional expression of approval. This narrative aligns with research showing that those who perceived their supervisors were fair and supportive were more 
likely to report lower just earnings, which suggests that "recognition and highquality relationships compensate for lower monetary rewards" (Sauer \& May, 2017, p. 52). Thus, in situations where increases in monetary rewards are not feasible, employers may still be able to mitigate feelings of underreward among their employees and avoid its potential downstream consequences by cultivating interpersonal forms of recognition for their employees.

To conclude, our study elaborates on the forms of work-related contributions and needs that shape the just reward among contemporary workers. Our findings reveal that "downloaded" and "sideloaded" extra work shape greater expectation of rewards partly through feelings of overload, and rising cost of living and the associated financial strain also shape greater reward expectations. Furthermore, financial strain exacerbates the link between extra work and greater reward expectations. These discoveries are important because they expand the scope of what constitutes work effort and need, illuminate the processes of effort and need, and the ways in which effort and need considerations can combine synergistically to shape reward expectations. Documenting the antecedents of the just reward is critical in understanding the processes that determine individuals' perceptions of underreward, which has a variety of negative consequences for employees and organizations. Moving forward, we encourage researchers to continue integrating literatures on distributive justice, occupational health, and stress processes as well as insights from qualitative and quantitative approaches to document the conditions that determine workers' sense of what they should earn.

\section{Appendix}

See Tables 3 and 4.

Table 3 Distributive justice items in the 2017 Canadian Work, Stress, and Health Study (CANWSH)

\begin{tabular}{lc}
\hline Distributive justice questions & Response choices \\
\hline DJ1: "When you think about the pay you get for & $\begin{array}{c}\text { underpaid a lot; underpaid a little; paid about right; } \\
\text { overpaid a little; overpaid a lot }\end{array}$ \\
$\begin{array}{l}\text { your work, do you feel you are..." } \\
\text { DJ2: "Is your pay just? We are not asking how } \\
\text { much you would like to earn-but what you feel } \\
\text { is just given your skills and effort" a }\end{array}$ & $\begin{array}{l}\text { just for me; a little more than is just; much more } \\
\text { than is just }\end{array}$ \\
$\begin{array}{ll}\text { DJ3: "How fair is what you earn on your job in } \\
\text { much less than you deserve; somewhat less than you } \\
\text { comparison to others doing the same type of }\end{array}$ & $\begin{array}{l}\text { deserve; about as much as you deserve; somewhat } \\
\text { more than you deserve; much more than you }\end{array}$ \\
work you do?" b & deserve
\end{tabular}

a This item is adapted from the Social Inequality module of the 2009 International Social Survey Programme (ISSP)

${ }^{\mathrm{b}}$ This item is adapted from the U.S General Social Survey 
Table 4 Demographics of focus group participants $(N=22)$

\begin{tabular}{|c|c|}
\hline Gender & \\
\hline Men & 41 \\
\hline Women & 59 \\
\hline Race/ethnicity & \\
\hline White & 59 \\
\hline Non-white & 41 \\
\hline Age & \\
\hline $20-29$ & 5 \\
\hline $30-39$ & 14 \\
\hline $40-49$ & 18 \\
\hline $50-59$ & 41 \\
\hline $60-69$ & 23 \\
\hline Marital status & \\
\hline Married & 41 \\
\hline Not married & 59 \\
\hline Education & \\
\hline Less than a Bachelor's & 36 \\
\hline Bachelor's degree & 27 \\
\hline Graduate degree & 36 \\
\hline Personal income & \\
\hline Less than $\$ 20,000$ & 5 \\
\hline$\$ 20,000-\$ 39,999$ & 23 \\
\hline$\$ 40,000-\$ 59,999$ & 9 \\
\hline$\$ 60,000-\$ 79,999$ & 36 \\
\hline$\$ 80,000-\$ 99,999$ & 18 \\
\hline$\$ 100,000$ or more & 9 \\
\hline
\end{tabular}

Funding Funding from the University of Toronto Tri-Council Bridge Funding supports this research (Scott Schieman, PI).

\section{References}

Aalberg, T. (2003). Achieving justice: Comparative public opinion on income distribution. Brill.

Adams, J. S. (1963). Toward an understanding of inequity. Journal of Abnormal and Social Psychology, 67(5), 422-436.

Alves, W. M., \& Rossi, P. H. (1978). Who should get what? Fairness judgments of the distribution of earnings. American Journal of Sociology, 84(3), 541-564.

Ash, T. G., \& Zimmermann, A. (2020, May 6). In crisis, Europeans support radical positions. eupinions. https://eupinions.eu/de/text/in-crisis-europeans-support-radical-positions

Auspurg, K., \& Hinz, T. (2015). Factorial survey experiments. Sage.

Auspurg, K., Hinz, T., \& Sauer, C. (2017). Why should women get less? Evidence on the gender pay gap from multifactorial survey experiments. American Sociological Review, 82(1), 179-210. 
Badawy, P., \& Schieman, S. (2020). Controlling or channeling demands? How schedule control influences the link between job pressure and the work-family interface. Work and Occupations, https:// doi.org/10.1177/0730888420965650.

Bakker, A. B., \& Demerouti, E. (2017). Job demands-resources theory: Taking stock and looking forward. Journal of Occupational Health Psychology, 22(3), 273-285.

Blair-Loy, M. (2009). Work without end? Scheduling flexibility and work-to-family conflict among stockbrokers. Work and Occupations, 36(4), 279-317.

Boulding, K. E. (1962). Social justice in social dynamics. In R. B. Brandt (Ed.), Social justice. (pp. 73-92). Prentice Hall.

Clay-Warner, J., Reynolds, J., \& Roman, P. (2005). Organizational justice and job satisfaction: A test of three competing models. Social Justice Research, 18(4), 391-409.

Colquitt, J. A., Conlon, D. E., Wesson, M. J., Porter, C. O. L. H., \& Ng, K. Y. (2001). Justice at the millennium: A meta-analytic review of 25 years of organizational justice research. Journal of Applied Psychology, 86(3), 425-445.

Cook, K. S., \& Yamagishi, T. (1983). Social determinants of equity judgments: The problem of multidimensional input. In D. M. Messick \& K. S. Cook (Eds.), Equity theory: Psychological and sociological perspectives. (pp. 95-126). Praeger Scientific Press.

D’Ambrosio, C., Clark, A. E., \& Barazzetta, M. (2018). Unfairness at work: Well-being and quits. Labour Economics, 51, 307-316.

de Boer, E. M., Bakker, A. B., Syroit, J. E., \& Schaufeli, W. B. (2002). Unfairness at work as a predictor of absenteeism. Journal of Organizational Behavior, 23(2), 181-197.

Deutsch, M. (1975). Equity, equality, and need: What determines which value will be used as the basis of distributive justice? Journal of Social Issues, 31(3), 137-149.

Evans, M. D. R., Kelley, J., \& Peoples, C. D. (2010). Justifications of inequality: The normative basis of pay differentials in 31 nations. Social Science Quarterly, 91(5), 1405-1431.

Falk, A., Kosse, F., Menrath, I., Verde, P. E., \& Siegrist, J. (2018). Unfair pay and health. Management Science, 64(4), 1477-1488.

Gatskova, K. (2013). Distributive justice attitudes in Ukraine: Need, desert or social minimum? Communist and Post-Communist Studies, 46, 227-241.

George, J., \& Wallio, S. (2017). Organizational justice and millennial turnover in public accounting. Employee Relations, 39(1), 112-126.

Geurts, S. A., Schaufeli, W. B., \& Rutte, C. G. (1999). Absenteeism, turnover intention and inequity in the employment relationship. Work \& Stress, 13, 253-267.

Greene, J. C., Caracelli, V. J., \& Graham, W. F. (1989). Toward a conceptual framework for mixedmethod evaluation designs. Educational Evaluation and Policy Analysis, 11(3), 255-274.

Hegtvedt, K. A. (2018). Justice frameworks. In P. J. Burke (Ed.), Contemporary social psychological theories. (2nd ed., pp. 54-80). Stanford University Press.

Hermkens, P. L. J., \& Boerman, F. A. (1989). Consensus with respect to the fairness of incomes: Differences between social groups. Social Justice Research, 3(3), 201-215.

Hu, Q., Schaufeli, W. B., \& Taris, T. W. (2013). Does equity mediate the effects of job demands and job resources on work outcomes? An extension of the job demands-resources model. Career Development International, 18(4), 357-376.

ISSP Research Group. (2012). International social survey programme: Social inequality IV-ISSP 2009. [Data file]. Retrieved from https://dbk.gesis.org/dbksearch/sdesc2.asp?no=5400.

Jasso, G. (1978). On the justice of earnings: A new specification of the justice evaluation function. American Journal of Sociology, 83(6), 1398-1419.

Jasso, G., \& Rossi, P. H. (1977). Distributive justice and earned income. American Sociological Review, 42(4), 639-651.

Jasso, G., Törnblom, K. Y., \& Sabbagh, C. (2016). Distributive justice. In C. Sabbagh \& M. Schmitt (Eds.), Handbook of social justice theory and research. (pp. 201-218). Springer.

Kelly, E. L., \& Moen, P. (2020). Overload: How good jobs went bad and what we can do about it. Princeton University Press.

Kittel, B. (2020). Need-based justice: A sociological perspective. In S. Traub \& B. Kittel (Eds.), Needbased distributive justice: An interdisciplinary perspective. (pp. 91-131). Springer.

Krueger, R. A., \& Casey, M. A. (2014). Focus groups: A practical guide for applied research. (5th ed.). Sage.

Lamm, H., \& Schwinger, T. (1980). Norms concerning distributive justice: Are needs taken into consideration in allocation decisions? Social Psychology Quarterly, 43(4), 425-429. 
Lamm, H., \& Schwinger, T. (1983). Need considerations in allocation decisions: Is it just? The Journal of Social Psychology, 119(2), 205-209.

Leventhal, G. S. (1980). What should be done with equity theory? New approaches to the study of fairness in social relationships. In K. J. Gergen, M. S. Greenberg, \& R. H. Willis (Eds.), Social exchange: Advances in theory and research. (pp. 27-55). Plenum Press.

Leventhal, G. S., Karuza, J., Jr., \& Fry, W. R. (1980). Beyond fairness: A theory of allocation preferences. In G. Mikula (Ed.), Justice and social interaction. (pp. 167-218). Springer.

Liebig, S., Sauer, C., \& Friedhoff, S. (2015). Using factorial surveys to study justice perceptions: Five methodological problems of attitudinal justice research. Social Justice Research, 28, 415-434.

Liebig, S., Sauer, C., \& Schupp, J. (2012). The justice of earnings in dual-earner households. Research in Social Stratification and Mobility, 30, 219-232.

Morgan, D. L. (2014). Integrating qualitative and quantitative methods: A pragmatic approach. Sage.

Narisada, A. (2017). Socioeconomic status and the relationship between under-reward and distress: Buffering-resource or status-disconfirmation? Social Justice Research, 30(3), 191-220.

Narisada, A. (2019). The social antecedents and consequences of the sense of distributive injustice. [Doctoral dissertation, University of Toronto]. ProQuest Dissertations Publishing.

Narisada, A. (2020). Job pressure, the work-family interface, and the sense of distributive injustice: An elaboration of work-related inputs among 21st century workers. Social Psychology Quarterly, 83(2), 107-128.

Narisada, A., \& Schieman, S. (2016). Underpaid but satisfied: The protective functions of security. Work and Occupations, 43(2), 215-255.

Pearlin, L. I. (1983). Role strains and personal stress. In H. Kaplan (Ed.), Psychosocial stress: Trends in theory and research. (pp. 3-32). Academic Press.

Pearlin, L. I. (1989). The sociological study of stress. Journal of Health and Social Behavior, 30(3), 241-256.

Pearlin, L. I., Menaghan, E. G., Lieberman, M. A., \& Mullan, J. T. (1981). The stress process. Journal of Health and Social Behavior, 22(4), 337-356.

Price, R. H., Choi, J. N., \& Vinokur, A. D. (2002). Links in the chain of adversity following job loss: How financial strain and loss of personal control lead to depression, impaired functioning, and poor health. Journal of Occupational Health Psychology, 7(4), 302-312.

Robbins, J. M., Ford, M. T., \& Tetrick, L. E. (2012). Perceived unfairness and employee health: A meta-analytic integration. Journal of Applied Psychology, 97(2), 235-272.

Sachweh, P. (2012). The moral economy of inequality: Popular views on income differentiation, poverty and wealth. Socio-Economic Review, 10, 419-445.

Sauer, C., \& May, M. J. (2017). Determinants of just earnings: The importance of comparisons with similar others and social relations with supervisors and coworkers in organizations. Research in Social Stratification and Mobility, 47, 45-54.

Schneider, S. M., \& Valet, P. (2017). Relative standards of distributive justice: How social comparison orientations moderate the link between relative earnings and justice perceptions. Social Psychology Quarterly, 80(3), 276-287.

Schunck, R., Sauer, C., \& Valet, P. (2015). Unfair pay and health: The effects of perceived injustice of earnings on physical health. European Sociological Review, 31(6), 655-666.

Shamon, H., \& Duilmer, H. (2014). Raising the question of 'who should get what?' again: On the importance of ideal and existential standards. Social Justice Research, 27, 340-368.

Siegrist, J. (1996). Adverse health effects of high-effort/low-reward conditions. Journal of Occupational Health Psychology, 1(1), 27-41.

Siegrist, J., Starke, D., Chandola, T., Godin, I., Marmot, M., Niedhammer, I., \& Peter, R. (2004). The measurement of effort-reward imbalance at work: European comparisons. Social Science \& Medicine, 58, 1483-1499.

Small, M. L. (2011). How to conduct a mixed methods study: Recent trends in a rapidly growing literature. Annual Review of Sociology, 37(1), 57-86.

Tepper, B. J. (2001). Health consequences of organizational injustice: Test of main and interactive effects. Organizational Behavior and Human Decision Processes, 86(2), 197-215.

Törnblom, K., \& Kazemi, A. (2012). Advances in justice conflict conceptualization: A new integrative framework. In E. Kals \& J. Maes (Eds.), Justice and conflicts: Theoretical and empirical contributions. (pp. 21-51). Springer.

Valet, P. (2018). Social structure and the paradox of the contented female worker: How occupational gender segregation biases justice perceptions of wages. Work and Occupations, 45(2), 168-193. 
van Vegchel, N., de Jonge, J., Bosma, H., \& Schaufeli, W. (2005). Reviewing the effort-reward imbalance model: Drawing up the balance of 45 empirical studies. Social Science \& Medicine, 60(5), 1117-1131.

Wilkinson, R., \& Pickett, K. (2010). The spirit level: Why greater equality makes societies stronger. Bloomsbury Press.

Publisher's Note Springer Nature remains neutral with regard to jurisdictional claims in published maps and institutional affiliations. 